hold-up, which invariably increases with increasing liquid rates, yields substantially the same values of $h_{D}$ for the given packing and liquid rates, irrespective of whether the liquid is mercury, 'Cerrobend' or water. This trend is illustrated in Fig. 1, which also shows that the results for water irrigation of a wetted packing, and those of 'Cerrobend' at different temperatures, all lie on substantially the same general plot. An explanation of the observation is being deferred pending analysis of further data.

The results of static hold-up measurements obtained in the present investigation and those measured previously ${ }^{4}$ with mercury are compared in Table 1.

Table 1. Characteristic Results for Stratic Hold-up in 2-in. Bed. Zero Gas-RATE. 12-IN. PACKed Height

Packing Water hold-up (ml.)

Packing
$\frac{1}{4}$-in. steel rings
$\frac{1}{4}$-in. porcelain rings
$\frac{1}{4}$-in. porcelain berl sad

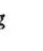

18

berl saddles 18 (42)*

18
$15(35)^{*}$
$18(42)^{*}$ Mercury

'Cerrobend'

* Results obtained under wetting conditions. along the $b$-axis and three-dimensional data collected using the Weisenberg camera. The intensities were estimated visually and the different levels scaled together by comparison with measurements made on the linear diffractometer ${ }^{4}$.

A sharpened three-dimensional Patterson function was calculated using the same sharpening function as that described by Jacobson et al. ${ }^{5}$ in their investigation of cellobiose. The increased resolution of small peaks from the sharpening enabled the Patterson to be solved for 10 out of the 15 atoms by using Buerger's ${ }^{6}$ Minimum function. A weighted ${ }^{7}$ Fourier synthesis of the [010] electron density projection was calculated using the signs determined by these 10 atoms and the remaining 5 showed up immediately. The agreement at this stage was $R=\frac{\Sigma \| F_{0}|-| F_{c}||}{\Sigma\left|F_{0}\right|}=53.4$ per cent. The structure was refined in two dimensions by difference Fouriers and least squares to 22 per cent, at which stage the third co-ordinates wore estimated from a trial modol and tho refinement

The results in Table 1 show that for the system considered it would appear un. justified to assume a similarity between mercury and molten 'Corrobend' in extrapolating the static hold-up measurements. Because the two are both liquid metals and, as such, have vastly different physical properties to water (or organic liquids) seems to be insufficient condition for assuming that mercury would yield better estimates for molten 'Cerrobend' than would the results obtained for water irriga. tion. As Table 1 shows, for the system investigated here, the reverso appears to hold.

Therefore, there seems to be an apparont need to exercise caution when extrapolating liquid metal hold-ups, especially the static hold-up, obtained with room temperature liquids, to molten metals which are supposedly being simulated in the laboratory.

Incorrect estimates of hold-up results, besides being erroneous, may lead to spurious interpretation of liquid metal heat and mass transfer mechanisms in packed beds.

\section{N. Standish}

School of Metallurgy, University of Otago, Dunedin, New Zealand.

${ }^{1}$ Shavrin, S. V., et al., Izvest. V.U.Z. Ferrous Metal (lj.S.S.R.), No. 9, 54 (1962).

${ }^{2}$ Gardner, G. C., Chem. Eng. Sci., 5, 101 (1956).

${ }^{3}$ Warner, N. A., Chem. Eng. Sci., 11, 149 (1959).

' Standish, N., N.Z. J. Sci., 6, 215 (1963).

${ }^{5}$ Elliott, J. F., et al., J. Metals, 4, 709 (1952).

- Kukarin, A. S., and Kitaev, B. I., Izvest. V.U.Z. Ferrous Metals (U.S.S.R.), No. 12,20 (1962).

\section{CRYSTALLOGRAPHY}

\section{Crystal Structure of $\mathbf{N}$-Acetylglucosamine}

THE crystal structure of $N$-acetylglucosamine, $\mathrm{C}_{8} \mathrm{H}_{15} \mathrm{O}_{6} \mathrm{~N}$, has been investigated in connexion with the work on lysozyme proceeding in this laboratory ${ }^{1}$. Salton ${ }^{2}$ and others have shown that $N$-acetylglucosamine is a basic constituent of the bacterial cell walls of Micrococcus lysodeikticus, the most commonly used substrate of lysozyme (muramidase), and Wenzel et al. ${ }^{3}$ have reported that this compound inhibits the action of the enzyme. At a later stage it is hoped to relate the structure to those of lysozyme and its substrates in detail.

The crystals were found to be monoclinic, space group $P 2_{1}$ with unit cell dimensions $a=11 \cdot 18, b=4 \cdot 81, c=9 \cdot 65 \AA$; $\beta=113 \cdot 3^{\circ}$. The density as calculated on the basis of two molecules per unit cell, $1.54 \mathrm{~g} / \mathrm{c} . c$., was in close agreement with that observed, $\mathbf{1 \cdot 5 7} \mathrm{g} / \mathrm{c} . \mathrm{c}$. The crystal was mounted

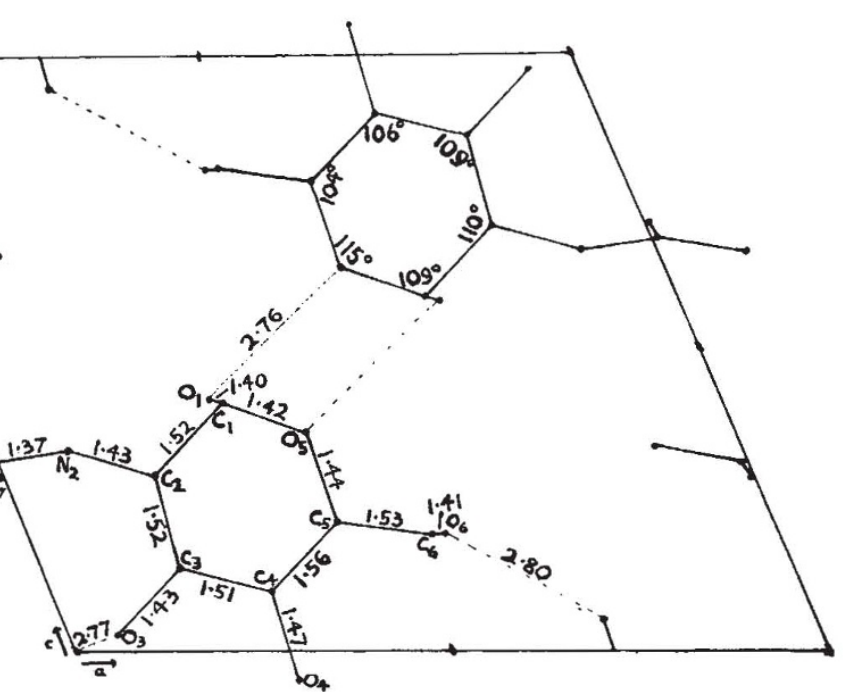
ylglucosamine showing bond-lengths in $\AA$, hydrogen bonds
and some bond-angles

continued in three dimensions. The present agreement is $18 \cdot 4$ per cent.

The structure and the bond-lengths and angles are shown in Fig. 1. The pyranose ring has the usual flattened chair form ${ }^{8}$ and the amide group is almost planar. There is a complete scheme of hydrogen bonding including a bond between the $\mathrm{CO}$ and $\mathrm{NH}$ of adjacent amide groups along the $b$-axis.

The refinem anisotropic temperature factors and the addition of hydrogen atoms, and the final results will be published elsewhere.

We thank Sir Lawrence Bragg and Prof. R. King for their advice, and Miss R. H. Fonn, Dr. R. Sarma and Mr. R. M. Simmons for use of their computor programmes.

\section{LOUISE N. JOHNSON}

D. C. Phillips*

Davy Faraday Research Laboratory, Royal Institution, 21 Albemarle Street, London, W.1.

* Medical Research Council External Staff.

${ }^{1}$ Blake, C. C. F., Fenn, R. H., North, A. C. T., Phillips, D. C., and Poljak, R. J. Nature, 196, 1173 (1962).

"Salton, M. R. J., and Ghuysen, J. M., Biochim. Biophys. Acta, 45, 355 (1960).

${ }^{3}$ Wenzel, M., Link, H. Y., and Schutte, E., Z. Physiol. Chem., 327, 13 (1962).

${ }^{4}$ Arndt, U. W., and Phillips, D. C., Acta Cryst., 14, 807 (1961).

s Jacobson, R. A., Wunderlich, J. A., and Lipscomb, W. N., Acta Cryst., 14, 598 (1961)

' Bucrger, M. J., Acta Cryst., 4, 531 (1951).

Woolfson, M. M., Acta Cryst., 9, 804 (1956).

$s$ Ramachandran, G. N., Ramakrishnan, C., and Sasisekharan, V., in Aspects of Protein Structure, Ramakrishnan, C., and Sasisekharan, V., in Aspects 